\title{
Cultura Cultura
}

Revista de Historia Teeria das deleas $\quad$ Revista de História e Teoria das Ideias

Vol. 32 | 2013

O surgimento da ciência moderna na Europa

\section{Leibniz y la química}

Leibniz and the Chemistry

\section{Juan Arana}

\section{OpenEdition}

\section{Journals}

Edición electrónica

URL: http://journals.openedition.org/cultura/1990

DOI: 10.4000/cultura.1990

ISSN: 2183-2021

\section{Editor}

Centro de História da Cultura

\section{Edición impresa}

Fecha de publicación: 2 diciembre 2013

Paginación: 105-123

ISSN: 0870-4546

\section{Referencia electrónica}

Juan Arana, «Leibniz y la química », Cultura [Online], Vol. 32 | 2013, posto online no dia 29 janeiro

2015, consultado a 19 abril 2019. URL : http://journals.openedition.org/cultura/1990 ; DOI : 10.4000/ cultura. 1990

Este documento fue generado automáticamente el 19 abril 2019.

(c) CHAM - Centro de Humanidades / Centre for the Humanities 


\title{
Leibniz y la química
}

\author{
Leibniz and the Chemistry
}

Juan Arana

1 La química ocupa un lugar marginal en la vida y obra de Leibniz. Marginal, pero significativo y revelador de su personalidad como pensador y protagonista de la vida intelectual del siglo XVII. No compuso muchos escritos relativos a esta disciplina, pero hay indicios de que le consagró bastante atención, porque conocía las obras de los principales autores antiguos y modernos, ${ }^{1}$ estaba puntualmente informado de las más recientes innovaciones e intervino con autoridad en las discusiones de experimentalistas y teóricos. Aunque dejásemos a un lado sus aportaciones matemáticas y físicas, las contribuciones al desarrollo de la química le habrían ganado un puesto relevante en la historia de la ciencia. Con ser esto importante, el mayor interés que encierra el estudio de Leibniz como químico es que ilumina un periodo crucial en la constitución de la química como ciencia solvente y madura. A la sazón estaba incluso más atrasada que la geología o la biología. En cambio, cien años después se convirtió en un saber parangonable con cualquier otro en el plano teórico, en tanto que sus repercusiones prácticas lo pusieron a la cabeza de la revolución industrial y de las trasformaciones experimentadas por el mundo en el siglo XIX. ${ }^{2}$

2 Sería excesivo pretender que Leibniz desempeñó un papel decisivo en esta trasformación, pero sin duda aportó algo más valioso que el descubrimiento de una ley o la introducción de cualquier técnica experimental: introdujo sensatez y espíritu crítico cuando la esperanza de obtener la piedra filosofal o el elixir de la vida todavía encandilaba a las mejores cabezas, como Boyle o Newton (Keynes, 1947). La transición de la alquimia a la química ha sido uno de los procesos más largos y costosos de la evolución del espíritu humano (Read, 1960) y sus fases más delicadas corresponden precisamente a los años de actividad de Leibniz. Es legítimo afirmar que se encontró con una actividad esotérica no muy alejada de la magia y dejó una disciplina fiable y prometedora. Examinemos qué puso de su parte para que dicha transformación tuviera lugar. 
3 Hay cuatro momentos en la vida de Leibniz de especial proximidad a este saber en rápida evolución. El primero corresponde a 1666-1670, los años juveniles en que inicia su carrera de sabio errante acumulando erudición en los más diversos ámbitos. La presencia de la química en esta fase inicial e iniciática queda atestiguada en numerosas consideraciones de la Nueva hipótesis física (1670).

4 Tras un interregno en que otros temas (matemáticos, políticos, mecánicos, teológicos, etc.) se vuelven prioritarios, hay una vuelta a la química - y en la vertiente más empírica - cuando regresa a Alemania y trata de servir a su príncipe en todos los frentes. Entre 1677 y 1679 se relaciona en particular con Steno, Crafft y Brandt, interviene decisivamente en la difusión del descubrimiento y producción del fósforo y efectúa algunas reflexiones importantes sobre los principios teóricos y metodológicos de la química.

5 En años sucesivos (1680-1685) este campo de investigación se subordina a otros relativos a la geología y la ingeniería, debido al trabajo que Leibniz desempeña por cuenta de los duques de Brunschweig-Lüneburg en las minas del Hartz. No olvida por ello las especulaciones teóricas, de lo cual deja constancia en su Protogaea (1691-1693). El fiasco en que desembocaron las actividades mineras, que estuvieron cerca de llevarle a la ruina, hicieron que el interés por la química, si no extinguido, quedara al menos bastante amortiguado en beneficio de otros campos más fructíferos y menos onerosos.

6 Por último, Leibniz llevó a cabo algo así como una puesta en limpio de sus averiguaciones en la correspondencia con Nikolaus Hartsoeker (1706-1712) e incluso efectuó una labor pionera como cronista de la química con la memoria Historia de la invención del fósforo (1710).

7 Nuestro conocimiento de los inicios de Leibniz en la química es tan incierto como el estado en que se encontraba la disciplina a mediados del siglo XVII. Patrimonio de los amigos de lo oculto, cuando no de simples timadores y farsantes, no era fácil abrirse camino en esa espesa selva de desconfianzas y supercherías. El primer episodio del que hay noticia tuvo lugar en 1667. Con tintes casi de leyenda se habla de la incorporación del joven doctor a una sociedad secreta de practicantes de la alquimia en Nürenberg, quizá afiliada a la misteriosa hermandad de los rosacruces. ${ }^{3}$ Eckhart, secretario del filósofo, relató en un esbozo biográfico escrito en $1717^{4}$ que Leibniz empleó un truco que recuerda el empleado por Sokal para desenmascarar presuntos fraudes intelectuales: consultó libros del género y se familiarizó con su oscuro lenguaje; luego redactó de una forma que él mismo no entendía un escrito solicitando la admisión al presidente de la sociedad, el cual (el clérigo Daniel Wülfer) creyó que Leibniz era un iniciado y no sólo lo recibió con los brazos abiertos, sino que lo nombró secretario, otorgándole incluso una pensión (Guhrauer, 1966: I, 46). Las indicaciones no son claras ni seguras, aunque muchos dieron por descontado que Leibniz había sido tanto un alquimista como un rosacruz..$^{5}$ George Ross, después de estudiar minuciosamente toda la documentación disponible, concluye que todo eso es obra de la imaginación. Lo que permanece en pie es que cuando era joven Leibniz se sintió atraído por la alquimia y aprendió sus principios (Ross, 1974: 245).

8 El único documento seguro y fehaciente es el que el propio interesado redactó y publicó en 1671 con el título de Nueva hipótesis física, después de presentarlo a la Royal Society de Londres para avalar su condición de intelectual serio. Sin duda es uno de sus trabajos más perecederos. Con posterioridad tuvo que desdecirse de muchas tesis allí defendidas. Pero no es una contribución menor la voluntad de someter a discusión abierta las grandes 
cuestiones de la química, cuando todavía en 1676 el mismísimo Newton aconsejaba a Robert Boyle guardar silencio al respecto, "puesto que hay otras cosas además de la transmutación de los metales que nadie excepto ellos [los auténticos filósofos herméticos] comprenden» (Newton, citado por Christianson, 1986: 257). Leibniz siempre fue partidario de exponer a la luz pública los puntos más controvertidos de la investigación. En esto aventaja a su insigne competidor inglés y patrocina la nueva ciencia por encima de cómo lo hicieron Galileo o Kepler.

A la sazón la alquimia seguía tan viva como en el pasado, pero ya se tenía conciencia de que, independientemente de que fuera o no posible trasmutar el plomo en oro o encontrar el secreto de la eterna juventud, el estudio de las trasformaciones de las sustancias tenía en sí mismo interés teórico y práctico. El mismo Newton lo sabía bien (Christianson, 1986: 235) y Robert Boyle había extendido el acta fundacional de una química desentendida de cualquier prodigio fantasmagórico con su obra El químico escéptico (1661). Que en su primer escrito demuestre no sólo conocer, sino asumir la enseñanza fundamental de aquel libro avala tanto la instrucción como la temprana madurez de Leibniz:

Pero la gran mayoría de estas teorías se propone de manera tan intricada, tan ambigua, que hasta el presente ha resultado casi imposible llegar a definiciones concordes de los términos. Esta variedad de términos en química la criticó de manera brillante el doctísimo Boyle en su obra El químico escéptico (OFC: 8, 41; A VI 2, 240).

El problema de la nomenclatura era crucial tanto para la química como para la historia natural. Los biólogos lo resolvieron en la Ilustración gracias a un esfuerzo mancomunado que culminó Linneo (Arana, 1995), pero los químicos no lograrían algo parecido hasta después de Lavoisier, Dalton y Berzelius, esto es, ya entrado el siglo XIX.

11 Fijar una terminología inequívoca es una condición previa de posibilidad para que una ciencia se constituya como tal. Sin embargo, hay otra todavía más esencial: la determinación de un objeto propio y separado. En el siglo XVII el objeto de la naciente química estaba completamente mezclado y confundido con el de la física y la medicina, de lo cual hay muchas evidencias en la Nueva hipótesis física: se compara el magnetismo con la combustión (OFC: 8, 38-39; A VI 2, 239-240), la repulsión con la fermentación (OFC: 8, 39; A VI 2, 240), la sanación con la neutralización química (OFC: 8, 50; A VI 2, 245), el arqueo de los químicos con el éter de los físicos (OFC: 8, 68; A VI 2, 255), etc. En el fondo, la única especificidad que tenía la química era la que le daban las operaciones de sus nefandos ancestros los alquimistas: calcinación, fijación, disolución, digestión, destilación, sublimación, separación, ceración, fermentación, multiplicación, proyección... Sin embargo, cuando se eliminaban las connotaciones equívocas no resultaba fácil diferenciar estas maniobras de las más prosaicas manipulaciones físicas (partición, compresión, fragmentación, mezcla, etc.). Es por supuesto un hecho que ciertas sustancias reaccionan y se combinan más o menos espontáneamente cuando se reúnen, especialmente si hay adición de calor o alguna sustancia catalizadora. En cambio otras permanecen pasivas, por próxima que sea su vecindad y alta la temperatura. ¿Basta eso para fundamentar la existencia de dos ciencias autónomas? Cuando la química moderna consiguió constituirse como tal, se admitió de una forma bastante arbitraria y convencional que las transformaciones físicas consistían en meros desplazamientos y procesos de separación y síntesis, los cuales no trascendían el nivel de las moléculas, mientras que la generación y corrupción de estas interesaba a un nivel más básico de la organización material, centrado a partir de Dalton en la noción de átomo. De acuerdo con ello, los cambios 
supramoleculares eran competencia de los físicos; los submoleculares, de los químicos. Solución salomónica, provisional y poco satisfactoria, porque siempre hubo zonas ambiguas, como los fenómenos de ionización y electrolisis. El fracaso definitivo del esquema aconteció cuando se descubrió un nivel infraquímico - por así decir - que involucraba transformaciones subatómicas y que, en lugar de asignarse a los químicos, fue acaparado por los físicos, como una prolongación natural de sus investigaciones sobre electricidad (al fin y al cabo, fue un físico, J. J. Thomson, quien descubrió el electrón, primera partícula subatómica). Hay quien sostiene con toda seriedad que desde la formulación por Paul Dirac de la electrodinámica cuántica en 1928, la teoría química ha sido colonizada por la física y hasta convertida en uno de sus capítulos, ${ }^{6}$ aunque por supuesto sigue conservando autonomía práctica en el rango de fenómenos que tiene asignado.

Resulta muy llamativo encontrar algunos rasgos de la situación posterior de la disciplina en la fase pre-epistémica que le tocó vivir a Leibniz. En la vieja alquimia se mezclaban inextricablemente saberes y pseudosaberes. Paracelso y sus seguidores habían tratado de dar al conglomerado un aire menos fraudulento y más pragmático, aproximando alquimia y medicina en una especie de disciplina mixta (la iatroquímica). Los químicos escépticos (asumiendo la denominación de Boyle) se repartían entre los enemigos de cualquier exceso hermenéutico, que seguían las consignas desnudamente empiristas de Francis Bacon, y los que sin renegar de la experiencia buscaban en la mecánica inspiración para desterrar de una vez por todas las cualidades ocultas de la escolástica y las cualidades ocultísimas de la alquimia (el propio Boyle, que paradójicamente no renunció a los viejos ideales de trasmutación aurífera, pertenecía a este grupo).

Leibniz actuó como una caja de resonancia y escuchó todas las voces presentes en el escenario (al)químico de su tiempo. Por un lado estaba la vieja doctrina empédocleoaristotélica de los cuatro elementos (tierra, agua, aire, fuego). Por otro la dualidad alquimista de los principios mercúrico y sufuroso, enriquecida luego por el modelo de los tres principios paracélsicos (mercurio-azufre-sal), por no hablar de otras oposiciones (masculino-femenino, ácido-alcalino, etc.). Después de empaparse de toda la literatura, el joven sajón sucumbió a la tentación del sincretismo y procuró dar satisfacción a todos desde su propia concepción mecánica. Al decir esto no pretendo minusvalorar la impronta de otras tradiciones de pensamiento, en particular la corriente hermética que de un modo tan exhaustivo como convincente ha analizado Bernardino Orio de Miguel (Orio, 2002, especialmente: 218249). Pero al dar forma a su pensamiento es muy nítido que generalizó el concepto de «burbuja» hasta convertirlo en la primera formalización de la materia extensa:

Generalmente, entonces, el éter se encontrará también recogido en sus burbujas, ocultas bajo una forma ya sea líquida o seca [...]. Éste es el archaeus de Helmont, el rector de Tachen, el espíritu del mundo de otros; algunos lo llaman el tercer principio mercurial y le atribuyen esta nobilísima fuerza formadora o plástica, que por ejemplo se puede aislar en las semillas, en la sal común y, de manera especial, en el mercurio. [...] Este líquido etéreo, esta sal celestial - si creemos con Helmont que se puede obtener - verosímilmente ejerce tantas virtudes cuantas el propio Helmont honra en su alcahest o alcali est, de lo que debe juzgar la experiencia (OFC: 8, 44; A VI 2: 242).

Su complacencia no estaba reñida con la toma de posturas polémicas, que le servían para llevar hasta sus últimas consecuencias los axiomas promovidos por él: 
De ahí, pues, que aquella incondicionada teoría acerca del número de los principios fundamentales de los seguidores de Paracelso, sea la quinitas sea la trinitas, se vuelve muy sospechosa. [...] De manera que, en consecuencia, me temo que en el futuro ten dremos el número cuatro para los principios útiles: las burbujas vaciadas más grandes, o sea un alcalino o sal sólida; las burbujas henchidas más grandes, o el ácido o azufre sólido; las burbujas vaciadas más pequeñas, o el alcalino volátil; las burbujas henchidas más pequeñas, o el ácido volátil (OFC: 8, 47; A VI 2, 244). estatuto epistémico de la química. Comienza retrotrayéndose al matematicismo de Galileo: «aquí se puede admirar el modo de proceder de Dios que, en la armonía de las cosas, aplica el arte de la geometría» (OFC: 8, 67; A VI 2, 255). No parece muy congruente tal afirmación con el estado de crudo cualitativismo que reinaba en la química al uso. Pero de inmediato añade Leibniz que la inteligibilidad de la realidad cósmica presupuesta por este principio no tiene que aplicarse imperiosamente de un modo exhaustivo: «por la naturaleza de las cosas es imposible que un cuerpo cualquiera sea conocido en su totalidad» (Ibíd.). Para evitar que esta restricción arruine por completo la pretensiones cognitivas de la nueva ciencia propone circunscribir la transparencia inteligible a la dimensión aparente del mundo físico: «sucede que todas estas cosas, aunque no sean así en la realidad, se manifiestan con suma precisión al conocimiento sensible» (Ibíd.). Muy probablemente hay aquí un atisbo del concepto de «fenómeno bien fundado» que será clave para la concepción leibniziana madura de espacio, tiempo y materia. Por el momento sirve para proporcionar apoyo a la viabilidad de ciencias mixtas entre la física y la matemática, lo que fundamenta la esperanza de que la química tome algún día «el recto camino de la ciencia»:

...gracias a la magna munificencia divina, se pueden cultivar [...] la óptica, la música, la estática, la elástica, la ciencia relativa al ímpetu y al golpe, la miología (o ciencia del movimiento de los músculos), e incluso la pirotécnica y la mecánica entera y cualesquiera ciencias mixtas entre la física y la matemática (Ibíd.).

66 Kant negó en los Principios metafísicos de la ciencia de la naturaleza que la química «pueda devenir otra cosa que un arte sistemático o una doctrina experimental» (Kant, 1989: 32). Ciento quince años antes de esa fecha Leibniz se había mostrado mucho más perspicaz, puesto que antes de que estallara la Revolución francesa Lavoisier introduciría, gracias a sus precisas balanzas, la exactitud matemática en la calumniada disciplina. Una vez más el defecto de Leibniz fue haberse adelantado demasiado a su tiempo.

Con la teoría del movimiento concreto de la Nueva hipótesis física el Leibniz primerizo da la medida de cuán lejos puede llegar con sus teorizaciones. El que seis años más tarde desembarca en Hannover tras un traslado que será definitivo ha aprendido a asentar firmemente los pies en el suelo. Sus desvelos para procurar que el saber redunde en beneficio de la humanidad lo prueban sin lugar a dudas. Poco a poco va tejiendo una densa red de relaciones personales que será preciosa para sus objetivos. De la amistad con Johann Daniel Crafft, químico y emprendedor, vendrá su contribución positiva más eficaz al naciente saber. 

de llamativas propiedades. Con el recién descubierto fósforo resultaba fácil asombrar a los curiosos y congraciarse con los gobernantes. Crafft no era el inventor ni tenía particular interés en convertirse en un benefactor público: tan sólo pretendía sacar provecho de una coyuntura propicia. Bien relacionado, estaba al servicio de los electores de Sajonia y Brandenburgo (OFC: 8, 529; Dutens: II, 105) y se dedicó a pasear la novedad por Europa, mostrándola entre otros a los soberanos de Inglaterra y Hannover. También se la hizo conocer a Leibniz, quien, en lugar de pensar ante todo en su provecho particular o preocuparse de halagar a los poderosos, convenció a Craf $\mathrm{t}$ para que le revelara todo lo que sabía al respecto y se apresuró a ponerlo en conocimiento del público entendido: hizo llegar muestras de la sustancia a Huygens y Tschirnhaus; a través de ellos lo comunicó a la Académie des Sciences de París; por último redactó una nota que apareció en el Journal de Sçavants del 2 de agosto de 1677 (OFC: 8, 157-159; Lamarra: 15-16). En ese escrito relataba las propiedades fenoménicas del material en cuestión, pero también daba indicaciones sobre los que poseían el secreto de su fabricación, instándoles a divulgarlo en beneficio de toda la humanidad. Hay una anécdota que revela cuánto costaba en aquella época abrir paso a la simple verdad despojada de novelerías: el redactor del Journal unió la importante noticia trasmitida por Leibniz con otra relativa a una "piedra de serpiente» (sic), poderosa contra la mordedura de reptiles (OFC: 8, 159; Lamarra: 16). Cuatro años más tarde Leibniz participó a la misma revista con idéntico celo el descubrimiento de un «agua humeante» que había encontrado en el curso de sus trabajos mineros. Esta vez el Journal combinó el escueto informe del sabio alemán con la relación de las maravillas observadas por un tal Hansen en un gabinete holandés de curiosidades, que incluía pequeñas rémoras presuntamente capaces de detener grandes navíos y un frasco con un cadáver infantil de cuyo cráneo salía una cabeza de gato (OFC: 8, 180-181; Lamarra: 990).

Estas frivolidades no desalentaban a Leibniz, que prosiguió infatigable su trabajo de heraldo de los nuevos tiempos: a través de Crafft supo que el verdadero inventor era Hennig Brandt, de Hamburgo. Brandt era un alquimista que había encontrado el fósforo por casualidad, manipulando orina en su búsqueda infructuosa de la piedra filosofal. Se habían aprovechado de él tanto Crafft como Johann Kunckel (otro químico bien situado): ambos le sonsacaron el secreto para medro personal. Los tres constituyen buenos ejemplos del lamentable estado en que todavía se encontraban las investigaciones en este campo. A diferencia de Crafft, Kunckel tenía la suficiente falta de escrúpulos como para atribuirse la autoría de la invención. El desdichado Brandt, que como tantos otros dilapidó su patrimonio en alambiques y retortas, seguramente habría muerto en la miseria y el anonimato de no ser por Leibniz, que se puso en contacto con él, logró que su soberano le concediera una pensión vitalicia y lo contrató para poner en marcha en Hannover un laboratorio de fabricación de fósforo (OFC: 8, 525-526; Dutens: II, 103-104). Además de las compensaciones materiales restituyó la paternidad del hallazgo, logrando que en este caso la historia hiciera justicia y atribuyera el mérito al genuino descubridor de este elemento, número 15 de la tabla periódica. Bien se podría concluir que si Brandt fue el descubridor físico Leibniz fue el descubridor moral, aunque nuestro hombre poseía suficientes títulos de gloria para no tener que disputárselos a ningún otro. $Y$ en efecto no lo hizo: un motivo más para lamentar el inicuo trato que a su vez recibió de Fatio de Duillier y del propio Newton a propósito de la invención del cálculo.

21 Lo cierto es que la gente ocupada en estudiar y practicar los procesos químicos formaba una tropa muy quisquillosa. Leibniz, que al fin y al cabo era cortesano y diplomático de 
profesión, poseía exquisito tacto para no herir susceptibilidades y apaciguar desconfianzas. Aún así no pudo evitar en alguna ocasión ser víctima de las iras de aquellos misántropos, especialmente cuanto en aras de la honestidad tuvo que oponerse a sus pretensiones fraudulentas. El choque más sonado se produjo con Johann Joachim Becher, que tenía fama de ser el químico más importante de Alemania. Leibniz había tenido tratos con él desde 1671 (Müller, Krönert, 1969: 23). Entre otros proyectos, intercambiaron puntos de vista sobre mejoras en los carruajes (Ibíd:: 53). A la muerte de Becher apareció de su mano una sátira (1683) sobre las locuras de los inventores. Allí acusaba a Leibniz de pretender construir un vehículo capaz de viajar desde Hannover hasta Amsterdam en seis horas (o sea, más o menos lo que en la actualidad se tarda por tren o autopista) (Ibíd.: 69). El libelo llegó a manos del patrón de Leibniz, quien tuvo que defenderse alegando que se trataba de un infundio urdido por sentimientos de venganza, suscitados concretamente por un affaire relativo a la alquimia: «Estaba enfadado conmigo porque impedí un fraude alquímico que planeaba» (Guhrauer, 1966: I, 26). En efecto, en una carta a Christian Huygens del 8 de septiembre de 1679 Leibniz había comentado:

Habréis oído hablar de la empresa del señor Becher en Holanda consistente en extraer oro de la arena. Hay personas que la ven con buenos ojos. Sabréis que el señor Hudde es uno de los comisarios. El señor Becher dice que también trata con los franceses. Me gustaría saber si habéis oído hablar de ello en París. Por mi parte dudo del éxito, porque creo saber poco más o menos en qué consiste su experimento. Hay un vestigio de oro, pero no sé si hay algo de ganancia, porque él pretende que lo habrá en proporción más grande que pequeña, lo cual es paradójico (GM I, 20).

Bien se ve que estaba dispuesto a asumir el riesgo de malquistarse con personas influyentes y potencialmente peligrosas con tal de encarrilar la investigación química como era debido. En un plano muy diferente, hay un hecho adicional que certifica lo atinado de la posición de Leibniz. Contribuyó a establecer uno de los protocolos estandarizados de la química moderna cuando no se conformó con hacer que Brandt completara el proceso de fabricación del fósforo bajo su supervisión y reprodujo por sí mismo el proceso independientemente (Aiton, 1985: 119). Tal vez lo hiciera por prudencia (para descartar la sospecha de que Brandt pudiera haber disimulado en su demostración una maniobra esencial para el buen éxito del proceso), pero en tal caso con tanto mayor motivo habría que reconocer que contribuyó a asentar una de las reglas de oro del método experimental.

Los hechos hasta ahora expuestos avalan la conclusión de que Leibniz estaba familiarizado con el día a día de las prácticas experimentales en el campo de la química, interviniendo en ellas con dedicación y buen criterio, hasta convertirse en aliado de los científicos honrados y enemigo de los que tenían propósitos menos nobles que la búsqueda de la verdad. Hay sin embargo otro aspecto importante en su trabajo del que ya se encuentran algunos rasgos en la obra juvenil que he comentado: la reflexión teórica sobre el método y los objetivos de la investigación química. Se diría que cuando Leibniz contemplaba las ciencias se fijaba más en su porvenir que en su presente. Así se explica el optimismo (no reñido con el realismo) al juzgarlas, expresado entre otros muchos lugares en su Discurso concerniente al método de la certidumbre y el arte de inventar, donde incluye un párrafo para cantar las excelencias de la química: «La química, armada con todos los elementos, trabaja con éxito sorprendente para cambiar los cuerpos naturales de mil formas, que la naturaleza nunca les hubiera dado o en todo caso mucho más lentamente» (GP VII, 174-175). ¿Cómo pensaba contribuir a semejante revolución? Hay un manuscrito 
fechado en mayo de 1677 que lleva por título Sobre el modo de llegar al verdadero análisis de los cuerpos y a las causas de las cosas naturales. Contiene una breve pero sustanciosa síntesis de su pensamiento. Leibniz afronta con decisión el desconcierto teórico reinante provocado por el choque de cuatro factores contrapuestos:

a) un empirismo proveniente de las tradiciones alquímicas: lleno de contenidos, pero contaminado de añadidos irracionales.

b) un segundo empirismo conectado con las prácticas artesanas e industriales previas a la revolución científica: también preñado de contenidos, aunque privado de cualquier vuelo teórico.

c) un tercer empirismo ligado al programa baconiano: más depurado y con alguna pretensión teórica, pero por el momento ayuno de resultados.

d) un proyecto teórico ligado al racionalismo en diálogo con lo empírico: trataba de dar explicaciones mecánicas y oscilaba entre:

d1) la tendencia a metaforizar de la escuela cartesiana y

d2) el matematicismo no metafórico de Galileo y Newton.

El intento de Leibniz consiste básicamente en esbozar una síntesis de c), d1) y d2) para desde ella filtrar y reformular a) y b) salvando todo lo salvable.

Aparentemente el punto de partida es $\mathrm{d}$ ), porque introduce como primera providencia un postulado de inteligibilidad claramente comprometido con el mecanicismo:

Ante todo, tengo la certeza de que todo se hace por ciertas causas inteligibles, o sea por causas que podríamos percibir si nos las quisiera revelar un ángel. Pero como no percibimos con precisión más que el tamaño, la figura, el movimiento y la percepción misma, síguese que habrá que explicarlo todo por estas cuatro. Y como estamos hablando de cosas que parecen hacerse sin percepción, como las reacciones de los líquidos, el precipitado de las sales, etc., no hay sino explicarlas por el tamaño, la figura y el movimiento, es decir, mecánicamente. Y cuanto no pueda explicarse de este modo, habrá que referirlo a la acción de alguna cosa percipiente (OFC: 8, 162; GP VI, 265).

32 En este mundo, lo que no es espíritu (percepción) es materia (extensión). Las reacciones químicas nada tienen que ver con la actividad mental. Luego por fuerza habrán de reducirse a tamaño, figura y movimiento. Así se construye el silogismo mecanicista, que al menos tiene el mérito de cerrar definitivamente el paso a la magia, el psiquismo, el animismo y cualquier ensoñación quimérica. La expulsión de la alquimia del templo de la ciencia natural quedaba así decidida de una vez por todas.

Es interesante el recurso a "lo que nos quisiera revelar un ángel" porque salva la distancia entre la inteligibilidad quoad se y quoad nos. Si el universo es la creación de Dios, es evidente que Él ha de conocer sus entrañas más recónditas. Pero eso no garantiza que el hombre pueda emular dicho conocimiento. El «ángel» cumple entonces la función de demiurgo epistémico: no es responsable de la trasparencia cognitiva de la realidad creada, pero sostiene la esperanza de un conocimiento perfecto, que ya no es un conocimiento creador, sino reproductor. Obviamente es una concepción ligada a la cosmovisión cristiana, puesto que para los cristianos Dios no sólo creó el mundo con sabiduría, sino que además lo hizo con una sabiduría a nuestro alcance. Dejando a un lado hasta dónde llegaban las convicciones religiosas de Leibniz o de cualquier otro creador de la ciencia moderna, aceptar como un axioma dicha tesis era conditio sine qua non para poner en marcha el proyecto de una ciencia que todavía se encontraba en un estado no ya embrionario, sino 
de malformación congénita. «Podemos desandar el camino realizado para después volver a recorrerlo con celeridad y avanzar más allá de donde hemos partido». Eso era lo que proyectaban los nuevos químicos, desafiando un saber que, con todos sus defectos, tenía tras de sí una trayectoria milenaria. No tendría sentido siquiera planteárselo de no mediar una confianza casi ciega en la accesibilidad de los enigmas cósmicos, una vez aplicada la clave correcta. En el siglo XVII se creía casi unánimemente que dicha clave no podía ser otra que la ciencia de la extensión, la figura y el movimiento local. La mayoría lo daba por supuesto, otros lo asumían de modo implícito sin pensarlo. Leibniz tiene el mérito de reconocerlo explícitamente, lo cual supone un notable ejercicio de reflexión autocrítica.

Ahora bien, no bastaba con partir de principios genéricos: había que recurrir además a postulados más específicos. En el caso de la química, el problema a mediados del siglo XVII no era la penuria, sino el exceso de alternativas: había todo un plexo de causas, elementos y agentes en pugna. Leibniz intentó clarificar el panorama, abandonando el terreno de lo abstracto y pasando sin solución de continuidad a colocarse en la concreción que le permitía su familiaridad con la literatura y la práctica químicas. A su juicio la cuestión no era decidir a priori si era mejor partir de una, dos, tres, cuatro, cinco o quién sabe cuántas instancias originarias. Consideraba preferible empezar desde abajo, aceptando cuantas sustancias mostrara la experiencia y procurando establecer entre ellas una jerarquía por los procesos de trasformación unilateral o recíproca que se fueran estableciendo:
...bastará con determinar unas pocas especies a partir de las cuales podemos producir artificialmente otras varias especies y cualidades sensibles; porque, como entendiendo la causa se entiende el efecto, una vez que se hayan entendido cuidadosamente esas pocas especies, tomando cuidadosa nota de cuanto sucede en la preparación, resultará que podremos explicar perfectamente y como con una máquina, todas las demás especies (OFC: 8, 163; GP VI, 266).

Esta táctica vale para los elementos, pero también para los agentes: las causas eficientes, igual que las materiales, tienen que ser sometidas a un proceso de esclarecimiento y unificación. De un mecanicismo dogmático hemos pasado a otro crítico, que incluso llega a darse la mano con el baconismo en sentido amplio:

«Cuando, utilizando diversos ingredientes e instrumentos, se obtiene un mismo efecto, éste habrá que atribuirlo a lo que tienen en común aquellos» (Ibíd.). Para efectuar una síntesis teórica con fuentes de inspiración tan opuestas, Leibniz recu rre a una aplicación práctica de su ars combinatoria: hacer primero experimentos con un cuerpo único, luego con dos, con tres, etc., ensayando por orden todas las combinaciones y permutaciones posibles... Y para evitar la deriva analógica que acabó convirtiendo la física cartesiana en una novela, insiste en usar todos los medios necesarios para la cuantificación exacta de la experiencia: «Los cuerpos y sus preparados han de examinarse con órganos empíricos: balanza, termómetro, higrómetro, máquina pneumática...» (OFC: 8, 164; GP VI, 267).

Leibniz, en resumidas cuentas, fue en el último cuarto del siglo XVII uno de los pocos interesados en la química que tuvo la suficiente perspectiva para diseñar una estrategia con posibilidades de transformar en conocimiento riguroso lo que hasta entonces no pasaba de despropósito teórico y caos empírico. Por desgracia nunca fue hombre de un solo proyecto y careció del influjo necesario para convencer a otros de que desarrollaran sus ideas en orden a fundamentar la química. Por aquel tiempo acababa de hallar los fundamentos del cálculo infinitesimal (para el que sí encontró colaboradores de genio) y estaba dando los primeros pasos hacia la conformación de un nuevo sistema filosófico. La 
química debía quedar relegada, porque, como Leibniz vio con singular lucidez, sólo podía aspirar como máximo a convertirse en un saber penúltimo:

Aunque los cuerpos se subdividen hasta el infinito en otros cuerpos más sutiles, y aunque no quepa creer que se den elementos primeros, ello no debe hacemos desistir de la investigación de las causas, porque así como quien se sirve de piedras en la arquitectura no repara en los trocitos pequeñísimos de tierra interpuestos entre ellas [...] es de creer que los efectos de aquellos cuerpos sutilísimos sobre los cuerpos en que nos ocupamos, ya no tienen que ver con nuestros fenómenos más de lo que tienen que ver con la solidez de una fortificación los corpúsculos imperceptibles que componen la tierra (OFC: 8, 165; GP VI, 268).

Aunque inmadura todavía, la naciente química empezaba a orientarse hacia el atomismo, o al menos hacia el corpuscularismo. A la hora de barajar las diferentes opciones filosóficas Leibniz no podía transigir con una metafísica atomista, porque resultaba demasiado arbitraria y carente de fundamentos firmes desde el punto de vista de la razón pura. Pero el infinitismo que había aprendido a manejar gracias al nuevo cálculo permitía concebir la coexistencia de continuidad y discontinuidad: para dar cuenta de los cambios aparentes del mundo material no es preciso consumar el proceso de análisis infinito que exige el intelecto: entre lo fenoménico y lo nouménico podrían muy bien darse escalonamientos intermedios capaces de explicar la experiencia aunque sin dar cuenta de sí mismos. En ese caso, los elementos químicos se comportarían como si fuesen átomos (convirtiéndose en instancias explicativas autónomas a todos los efectos prácticos), mientras la razón quedaba libre para descomponerlos y proseguir el análisis más allá de la capacidad discriminadora de la experiencia. ${ }^{7}$ La futura distinción entre fuerzas primitivas y derivativas quedaba así prefigurada. La química en cierto sentido llegaba más lejos que la mecánica, pero en definitiva tendría que permanecer más cerca de esta que de la metafísica. La llamada cada vez más absorbente de la filosofía primera hizo que Leibniz se olvidara un poco de todo lo susceptible de distraerlo de ella, y la química quedó afectada por esta reordenación de sus prioridades.

Paradójicamente, aunque la química se distanciara del centro de gravedad teórico de Leibniz, en los años siguientes estuvo cada vez más cerca del práctico: entre 1680 y 1685 el filósofo pasó casi la mitad de su tiempo organizando trabajos de ingeniería para mejorar la explotación de las minas y la metalurgia en las montañas del Hartz. Como era un impenitente coleccionista de hechos, datos e ideas, no desaprovechó la ocasión y acumuló informaciones que con frecuencia rozaban el campo de la química. Podemos comprobarlo en el Protogaea, manuscrito confeccionado en la década de 1690, que recoge el fruto de sus pesquisas geológicas y paleontológicas, pero también supone un ejercicio interdisciplinar con puentes tendidos hacia la historia, la ingeniería y la química. Late el tema de la interrelación microcosmos-macrocosmos, ya que la Tierra toda es concebida en algunos pasajes como un laboratorio químico a gran escala: «estoy inclinado a asumir que con estos modestos modelos estamos recreando las grandes obras ejecutadas por la naturaleza, la cual tiene por alambiques las montañas y por hornos los volcanes » (OFC: 8, 312; Dutens: II, 210-211). La analogía es en este caso fértil, puesto que en los laboratorios tienen lugar procesos, de manera que en la naturaleza también hay una dimensión evolutiva, que Leibniz fue de los primeros en captar y desarrollar. De ello resulta una dignificación póstuma y simbólica de la alquimia: el hombre seguramente no puede producir cuerpos simples, pero Dios sí: todo el orbe del cosmos es su experimento. Sin embargo, ¡hay que tener cuidado!: el Autor del universo no improvisa de un día para otro las grandes transformaciones. 
En efecto, la naturaleza no es otra cosa que un Ars magna y no siempre resulta posible distinguir aquello que es natural de lo que fue producido [...] Y aunque no pretendo afirmar nada sobre el arte de la generación de los metales y de otros cuerpos simples similares, y no me atrevo a afirmar que nadie haya conseguido producir oro, plata, mercurio, ni siquiera sal, ni que los haya podido destruir completamente, pienso, sin embargo, que igual de raro sería sorprender a la naturaleza en pleno trabajo, porque normalmente no hace más que reunir y descubrir lo que antaño se formó en otro lugar. Pues temo que no se pueda dar crédito a lo que dicen algunos sobre el nacimiento de oro por la exposición al Sol de arenas ya lavadas; ni a partir de deshechos minerales o de láminas de pizarras enriquecidas exclusivamente por el paso del tiempo (OFC: 8, 310; Dutens: II, 209). pensar que Dios es el supremo artesano. Lo cual recorta poder explicativo a los portentos y milagros, sin incurrir por ello en una prometeica lucha contra lo sobrenatural. Pocos libros más serenos y objetivos que esta historia de la naturaleza que no renuncia sin embargo a ser también historia de la creación: a Dios lo que es de Dios y a la naturaleza lo que le corresponde de suyo. Es el tono y las coordenadas del discurso lo que acaso puede constituir la mejor aportación de Leibniz a unos saberes convulsos que arrastraban toda una historia de dramáticas vindicaciones.

Pocos autores merecieron como Leibniz gozar en paz y contento los frutos de una larga vida de esfuerzo en gran parte altruista. Pero el destino le negó cruelmente esta satisfacción. Tuvo que arrostrar como pocos la incomprensión cuando no la ingratitud de una época que le debía demasiadas cosas. En lo que se refiere a la química, haberse mantenido a cierta distancia de ella le permitió al menos efectuar un balance sereno y ayuno de reproches ajenos o propios. En la Historia de la invención del fósforo (1710) tomó la pluma para unir en una sola mano el oficio de cronista de una realidad vivida e historiador que juzga con perspectiva y amplitud de miras. Fundador de tantas disciplinas, Leibniz de alguna manera también lo es de la historia de la química. En una especie de pirueta final de aquel espíritu caleidoscópico, se permite insertar incluso una oda compuesta al fósforo ígneo (OFC: 8, 530-531; Dutens: II, 106-107). Pero a la vez no deja escapar la oportunidad de introducir finísimas observaciones críticas, como cuando advierte que cierta propiedad del fósforo puede servir como evidencia crucial para descartar la física cartesiana: «Este experimento conmovió fuertemente a los cartesianos, muy pocos de los cuales habían visto la piedra de Bolonia, porque pensaron que los rayos de luz eran pura presión y se propagaban instantáneamente, debido a que de golpe la luz parecía ser algo pesado y transportable» (OFC: 8, 524; Dutens: II, 102).

Co ya adelanté al principio de este trabajo, la correspondencia con Nikolaus Hartsoeker da ocasión a Leibniz para reafirmar calmosamente sus convicciones y conquistas, al menos en lo que concierne a la química. He aquí algunos extractos de aquel intercambio:

Estoy convencido de que no hay elementos de los cuerpos naturales, y considero que si pudiésemos percibir distintamente los corpúsculos los encontraríamos tan variados como los grandes, y eso hasta el infinito (carta del 12.12.1706; GP III, 488). Explicar la luz es explicar la mitad de la naturaleza del fuego (carta del 12.12.1706; GP III, 489). Los químicos no solo dividen la sal en ácido y álcali, sino que también reconocen las sales, que no son una cosa ni otra [...] Así tiendo a creer que ni uno ni otro es producido o destruido por nuestras operaciones, sino sólo amasado o disipado (carta del 4.10.1706; GP: III, 491). Pero confieso que todavía soy al respecto un poco químico escéptico como el Sr. Boyle lo era sobre muchas otras cosas en su libro que lleva ese título (carta sin fecha; GP: III, 494). Soy bastante del sentimiento 
de los que no admiten que hasta ahora conozcamos la producción y destrucción de los metales, de la sal común y del salitre y de algunos otros cuerpos de esta simplicidad. Sin embargo sólo lo creo así provisionalmente, no viendo la imposi bilidad de la cosa, y no me opongo a creer que son tan antiguos como el mundo (carta sin fecha; GP: III, 497). No tengo la menor esperanza de llegar a la trasmutación de los metales y no conozco experiencia alguna que la confirme. Pero para decir absolutamente que es imposible habría que tener pruebas (carta sin fecha; GP III, 500-501).

$Y$, en efecto, fue preciso esperar hasta los experimentos con rayos alfa realizados por Rutherford en Manchester, ya en el siglo XX, para confirmar que la vieja quimera alquímica nos era después de todo absolutamente descabellada. El viejo Leibniz es un químico escéptico, pero no un químico desengañado. Le ha tomado el pulso a los grandes misterios de la naturaleza; ha estudiado con imparcialidad múltiples propuestas de solución; ha puesto todo el empeño en distinguir el grano de la paja y también ha intentado cosechar algunas gavillas nuevas. Al final del camino se ha encontrado más sabio y más humilde que cuando empezó. Su química no es la panacea universal; tampoco el fruto más granado de su generación; pero Leibniz personifica como nadie la postura más digna de ser imitada en este y en muchos otros campos de la investigación.

\section{BIBLIOGRAFÍA}

E. J. Aiton, Leibniz. Una biografía, Madrid, Alianza Editorial, 1992.

E. Álvarez Muñoz, “Leibniz y las ciencias de la tierra”, Nicolás, J.A. (ed.), Leibniz y las ciencias empíri cas, Granada, Comares, 2011: 127-50.

J. Arana, "El concepto de vida en la biología de los siglos XVII y XVIII", Verdad, percepción, inmor talidad. Wahrheit, Wahrnehmung, Unsterblichkeit, Miscelánea en homenaje al Prof. W. Strobl, Valencia, 1995: 71-83.

G. E. Christianson, Newton, Barcelona, Salvat, 1986.

A. G. Debus, The Chemical Philosophy. Paracelsian Science and Medicine in the Sixteenth and Seventeenth Centuries, New York, Neale Watson Academic Publications, 2 vols, 1977.

D. Garber, "De ortu et antiquissimis fontibus Protogaeae Leibnizianae dissertatio: observation, exploration and natural philosophy, Nicolás, J.A. (ed.), Leibniz y las ciencias empíricas, Granada, Comares, 2011: 165-85.

W. Greiling, La química conquista al mundo, Madrid, Editorial Enciclopédica, 1954.

G. E. Guhrauer, Gottfried Wilhelm Freiherr con Leibniz. Eine Biographie, Hildesheim, Olms, 1966.

J. Horgan, El fin de la ciencia. Los límites del conocimiento en el declive de la era científica, Barcelona, Paidós, 1998.

I. Kant, Principios metafísicos de la ciencia de la naturaleza, Madrid, Alianza, 1989.

J. M. Keynes, «Newton, the Man», en Proceedings of the Royal Society Newton Tercentenary Celebrations, 15-19 July 1946, Cambridge, Cambridge University Press, 1947. 
H. Metzger, Newton, Stahl, Boerhaave et la doctrine chimique, Paris, Librairie scientifique et tech nique Albert Blanchard, (1930) 1974.

H. Morich-Clausthal, «Wie Leibniz Alchemist wurde», en Die Spinnstube, 4, 1927: 295-296.

K. Müller; G. Krönert, Leben und Werk von G.W. Leibniz. Eine Chronik, Fankfurt a. M., Klostermann, 1969.

J. A. Nicolás, S. Toledo (eds.), Leibniz y las ciencias empíricas. Leibniz and the empirical sciences, Granada, Comares, 2011.

B. Orio de Miguel, Leibniz y el pensamiento hermético. A propósito de los "Cogitata in Genesim" de F. M. van Helmont, Valencia, Universidad Politécnica, 2 vols. 2002.

H. Peters, Leibniz als Chemiker, München, Vogel, 1916.

J. Read, Por la alquimia a la química. Procesión de ideas y personalidades, Madrid, Aguilar, 1960.

G. M. Ross, «Leibniz and the Nurenberg Alchemical Society», en Studia Leibnitiana, 6, 1974: 222248.

F. Yates, El iluminismo rosacruz, México. F.C.E., 1981.

\section{NOTAS}

1. La lista de autores relacionados con la química o la alquimia citados o mencionados en la Nueva hipótesis física de Leibniz incluye a Jean Baptiste van Helmont, Kenelm Digby, Francesco Lana Terzi, Robert Boyle, Johann Joachim Becher, Basilio Valentín (Johann Thölde), Johann Baptist Groschedel, Jabir ibn Hayyan (Geber), Isaac Hollandus, Franciscus de le Boe (Sylvius), Johann Rudolf Glauber, Oton Tachenius, Francesco Travagini, Thomas Willis, Richard Lower, Francis Hall (Lynus), Cornelius van Drebbel y Niels Stensen (Steno).

2. Tan sólo las mejoras nutricionales que resultaron de la fabricación de abonos químicos, e higiénicas tras la consecución de jabones baratos, determinaron que en menos de cincuenta años la esperanza de vida en Europa subiera de 30 a 60 años (Greyling, 1954: 52).

3. Según Frances Yates, Leibniz sabía a través de Francis van Helmont que dicha fraternidad era en realidad una ficción, lo cual no le impidió asimilar algunos de sus signos de identidad, como las reglas de la Orden de Caridad que propuso fundar (Yates, 1981: 194).

4. J. G. von Eckhart, Lebensbeschreibung der Freyherrn von Leibniz, 1717.

5. Véase, por ejemplo: Morich-Claushal, 1927: 296.

6. Es la opinión, por ejemplo, de Gunther Stent (Horgan, 1998: 27).

7. Cabe documentar este contraste comparando los escritos que he comentado con el manuscrito de 1690 Demostración contra los átomos tomada del contacto entre los átomos (OFC: 8, 268272; GP: VII, 284-288): posee una estructura demostrativa more geométrico; no aporta ni un solo dato o argumento empírico; remite todo a consideraciones de física extensional y matemática pura. 


\section{RESÚMENES}

Este trabajo analiza la presencia de la química en el pensamiento leibniciano. Se valora su contribución al nacimiento de la nueva química y la superación de la vieja alquimia. Se analizan los principales escritos consagrados por el filósofo a esta problemática, para establecer cómo evoluciona y qué relaciones tiene con sus trabajos en otras disciplinas.

In the following paper it shall be analyzed the presence of Chemistry in the thought of Leibniz. His contribution to the birth of the new Chemistry and the subsequent overcome of the old Alchemy shall be assessed. Therefore, the main manuscripts, dedicated by the philosopher to this problematic, will be analyzed to establish how it evolves and which relations it has to his works in other disciplines.

\section{ÍNDICE}

Keywords: alchemy, science, chemistry; G. W. Leibniz

Palabras claves: alquimia, ciencia, química, G. W. Leibniz

\section{AUTOR}

\section{JUAN ARANA}

Universidad de Sevilla

Profesor de la Universidad de Sevilla, tiene tras de sí una larga trayectoria de trabajos sobre la evolución del problema de la unidad del conocimiento en el pensamiento moderno y contemporáneo. En relación a Leibniz ha editado dos recopilaciones: Escritos de dinámica (1991) y Escritos Científicos (2009), así como dos volúmenes colectivos, Treinta años de estudios leibnizianos (2002) y Leibniz: teoría y práctica de la interdisciplinariedad (2009). También ha publicado los artículos: El influjo de Descartes, Leibniz y Newton sobre idea kantiana de ciencia (1995), Orden religioso y orden político en el ecumenismo de Leibniz y Bossuet (2001), Sobre las relaciones entre mecánica y metafísica: Concepto y medida de fuerza (2002), Entender la libertad: Leibniz (2005), Leibniz: Teoría y práctica de la interdisciplinariedad (2009), The Impact of Leibniz on Enlightenment Sciences (2010), La herencia leibniziana y la disputa sobre el principio de mínima acción (2001).

Professor of the University of Seville, Juan Arana has led after him a long trajectory of works on the evolution of the problem of the unity of knowledge in Early Modern and Contemporary thought. Professor Arana has published two collections of G. W. Leibniz' works: Escritos de dinámica (1991) and Escritos Científicos (2009). And two collective volumes on his thought as well: Treinta años de estudios leibnizianos (2002) and Leibniz: teoría y práctica de la interdisciplinariedad (2009). He has also published the following papers: El influjo de Descartes, Leibniz y Newton sobre idea kantiana de ciencia (1995), Orden religioso y orden político en el ecumenismo de Leibniz y Bossuet (2001), Sobre las relaciones entre mecánica y metafísica: Concepto y medida de fuerza (2002), Entender la libertad: Leibniz (2005), Leibniz: Teoría y práctica de la interdisciplinariedad (2009), The Impact of Leibniz on 
Enlightenment Sciences (2010), La herencia leibniziana y la disputa sobre el principio de mínima acción (2001). 